\title{
Risks to patient safety associated with implementation of electronic applications for medication management in ambulatory care - a systematic review
}

\author{
Cheryl LL Carling*, Ingvild Kirkehei, Therese Kristine Dalsbø and Elizabeth Paulsen
}

\begin{abstract}
Background: The objective was to find evidence to substantiate assertions that electronic applications for medication management in ambulatory care (electronic prescribing, clinical decision support (CDSS), electronic health record, and computer generated paper prescriptions), while intended to reduce prescribing errors, can themselves result in errors that might harm patients or increase risks to patient safety.

Methods: Because a scoping search for adverse events in randomized controlled trials (RCTs) yielded few relevant results, we systematically searched nine databases, including MEDLINE, EMBASE, and The Cochrane Database of Systematic Reviews for systematic reviews and studies of a wide variety of designs that reported on implementation of the interventions. Studies that had safety and adverse events as outcomes, monitored for them, reported anecdotally adverse events or other events that might indicate a threat to patient safety were included.

Results: We found no systematic reviews that examined adverse events or patient harm caused by organizational interventions. Of the 4056 titles and abstracts screened, 176 full-text articles were assessed for inclusion. Sixty-one studies with appropriate interventions, settings and participants but without patient safety, adverse event outcomes or monitoring for risks were excluded, along with 77 other non-eligible studies. Eighteen randomized controlled trials (RCTs), 5 non-randomized controlled trials (non-R,CTs) and 15 observational studies were included. The most common electronic intervention studied was CDSS and the most frequent clinical area was cardio-vascular, including anti-coagulants. No RCTS or non-R,CTS reported adverse event. Adverse events reported in observational studies occurred less frequently after implementation of CDSS. One RCT and one observational study reported an increase in problematic prescriptions with electronic prescribing

Conclusions: The safety implications of electronic medication management in ambulatory care have not been established with results from studies included in this systematic review. Only a minority of studies that investigated these interventions included threats to patients' safety as outcomes or monitored for adverse events. It is therefore not surprising that we found little evidence to substantiate fears of new risks to patient safety with their implementation. More research is needed to focus on the draw-backs and negative outcomes that implementation of these interventions might introduce.
\end{abstract}

Keywords: Electronic interventions, Medication management, Computer prescribing, Prescribing errors, Patient safety

\footnotetext{
* Correspondence: chc@nokc.no

The Norwegian Knowledge Centre for the Health Services, PO Box 7004, St. Olavsplass, 0130 Oslo, Norway
}

\section{Biomed Central




\section{Background}

E-prescribing or the e-prescription (e-Rx) is defined in the Center for Medicare and Medicaid Services' "final rule" as ".... the transmission, using electronic media, of prescription or prescription-related information between a prescriber, dispenser, pharmacy benefit manager, or health plan, either directly or through an intermediary, including an e-prescribing network" [1]. The implementation of e-Rx has been heralded as a remedy for problems associated with paper-based prescribing that can result in suboptimal or harmful outcomes for patients (e.g. [2]). The world's first e-Rx for an ambulatory patient was transmitted from a physician's office to a community pharmacy in Sweden in 1983 and by the end of 2008 it was estimated that about $80 \%$ of all new prescriptions in ambulatory care in Sweden were e-Rxs [3]. Other implementations of e-prescribing are in the USA [4] and Norway [5]. Canada is hoping "to make e-prescribing a reality by 2015 " [6]. In addition to the e-Rx, the electronic health record (EHR) and clinical decision support systems (CDSS), both e-applications that can support clinicians' prescribing activities, have been widely implemented and are regarded as important means to reduce the number of errors in medication management. CDSSs are implemented with the intention of improving clinical decision making in diagnosis and treatment [7], often for the purpose of changing provider behaviour (e.g. [8]); or supporting rational decision making and/or accurate use of clinical logarithms $[9,10]$.

Systems with advanced clinical decision support integrated with the EHR have been acclaimed and supported by research as the interventions most likely to reduce adverse events in medication management; e.g. drug-drug interactions, allergic reactions and faulty dose calculations; to support adherence to best practice and to best support clinical decision making e.g. [11-16].

\section{Why there is a need for a systematic review}

Despite the above accolades, concern has been expressed that digital applications might facilitate or provide new opportunities for prescribing errors and adverse events (AEs) or adverse drug events (ADEs) (e.g. [2,17]. Errors have been attributed to those that occur during input and access of information, and to communication and coordination processes between coupled applications or between application and end-user [18]. Examples of errors are faulty algorithms for dose calculation; wrong default dosing or route; user-interface facilitated errors; fragmentation errors due to faulty integration between applications; programming errors; as well as "false expectations" of clinicians who rely too whole-heartedly on the system's capabilities [13,17,19-21].

Our scoping literature search did not identify systematic reviews or randomized studies in the field that might substantiate these assertions. One review that classified outcome type found only four of 30 included studies (1950 to
March 31, 2006) that assessed safety [22]. Another [23] lists adverse drug events (ADEs) and deaths as patient outcomes and identifies the studies in which AEs and monitoring for AEs were specified $\grave{a}$ priori. Although we found relevant reviews that explored the effectiveness and efficiency of organizational interventions (e.g. CDSS) on improving process or patient outcomes (e.g. [15], to our knowledge, there is no earlier systematic review of which the main objective is to identify adverse events or harms to patients caused by organizational interventions.

\section{Objectives}

The objective for this review was to gather evidence that might substantiate assertions that implementation of einterventions for medication management in ambulatory care introduces new risks to patient safety.

\section{Methods \\ Criteria for considering studies for this review Types of studies eligible for this review}

There is little guidance on methods to conduct systematic reviews to answer questions about adverse effects, adverse events or patient harms albeit a few methodological reviews explore the challenges (e.g. [24,25]) and the merits of including various study designs (e.g. [26,27]).

Randomized controlled studies are underused in evaluating medical informatics interventions because of constraints, e.g. "(1) ethical considerations, (2) difficulty of randomizing subjects, (3) difficulty to randomize by locations ........ (4) small available sample size" [28]. In line with this, our preliminary scoping search failed to locate any randomized controlled trials (RCTs) of e-applications in medication management in ambulatory care of which the object was to discover or measure adverse events or risks to patient safety. There is also convincing evidence that harms or adverse events are inadequately reported by randomized trials [29]. It is proposed that information on harms from both long-term prospective studies as well as RCTs should be used in identifying harms [26].

Based on the above and observations of other authors [30-34], we decided to include a wide assortment of study designs: randomized controlled trials (RCTs); nonrandomized trials with concurrent control (n-RCTs); controlled trials; uncontrolled or non-concurrent controlled trials; cohort studies; cross-sectional studies and other observational designs.

\section{Interventions, settings and participants Interventions}

The intervention had to comprise at least one of the following e-applications:

- electronic transmission of individual patients' prescriptions to a pharmacy or digital prescription repository accessible to community pharmacies (e-Rx), 
- computer generation of paper prescriptions from prescriber's computer (CGPRx) meant to be retrieved at the community pharmacy by the patient or her care giver,

or

- at least one of the following e-applications used at point-of-care and in real time during medication management, with or without e-Rx or CGPRx,: digital clinical decision support systems (CDSS). electronic health record (EHR).

In the research and discussion literature, the terms "eprescribing" and "computerized prescribing" are sometimes interchangeably used to label medication management systems that might comprise one or more IT applications. For example, a system designated as "electronic prescribing" used "electronic prescribing software" with "clinical decision support" to generate either a paper or a digital prescription [35]. Occasionally, it is not clear exactly which e-applications are operative when the label "e-prescribing" is used without more specification, e.g. [36].

In this review we define an electronic prescription $(\mathrm{e}-\mathrm{Rx})$ as the digital message sent by an authorized prescriber to a pharmacy or a digital prescription repository that is accessible to community pharmacies. A telefax to a pharmacy is one of the simplest forms of an eprescription. E-prescribing is the act of using electronic information processing, usually the personal computer (pc), to generate the e-prescription.

In this review we define CDSS as electronic access, via stationary or portable computer, including appliances like Palm Pilot, to any information that supports clinicians' prescribing or monitoring of a patient's medication regime at point-of-care [37] from simple drop-down formulary lists (so-called passive decision support) to sophisticated systems that access patient-specific data from the EHR and e.g. use clinical algorithms to compare prescribing to a knowledge base, generate patient-specific recommendations or trigger tailored e-alerts to the prescriber in real time, i.e. at the time of medication management (so-called active decision support). In summation, CDSS in this review includes all e-applications that support selection or dosing regimens of medications or monitoring of parameters relevant for medication management (therapeutic drug monitoring). Examples of CDSS are electronic reminders, alerts, medication pick-lists, formularies, dose calculators, medication regime management suggestions or guideline presentation. A CDSS can be stand-alone or coupled to the EHR and/or an e-prescribing application.

We use the Health Information Management System's Society's definition of the EHR [38]:
"The Electronic Health Record (EHR) is a longitudinal electronic record of patient health information generated by one or more encounters in any care delivery setting."

\section{Setting and participants}

We included publications written in English or a Scandinavian language published after 1994 that reported effects of or observations associated with the implementation of the e-applications under consideration and implemented in ambulatory care, (i.e. doctors' offices, outpatient clinics, emergency rooms, well-baby clinics), targeted at the clinician, (i.e. health practitioners authorized to prescribe medications, i.e. nurses, nurse practitioners, physician assistants, and physician) for the purpose of medication management in the broad sense, i.e. new prescribing (including vaccinations) or medication regime adjustments: or activities performed for the purpose of evaluation and modification of patients' therapeutic pharmacological regime, e.g. monitoring of relevant physiological and drug parameters. Eligible participants were doctors or nurses licensed or otherwise eligible to prescribe medications in the setting.

\section{Outcomes}

We included studies that reported quantifiable objective outcome measures and comprised:

- Harms or threats to patient safety defined as outcomes in the study methods section.

- Any adverse events, as defined by the investigators.

- Anecdotal reports of events that could signify threats to patient safety.

Outcomes could be:

- Process of care: e.g. unsafe prescribing.

- Patient outcomes: e.g. mortality; morbidity, e.g. major bleeds, thrombotic events; adverse drug events (ADEs): e.g. unintended effects of drugs including drug-drug and drug-disease interactions; clinical course e.g. admission to specialist facility, emergency room visit.

- Technological outcomes: e.g. errors in transmission, errors in algorithm programming.

Criteria for exclusion were:

- studies performed in an in-patient setting or a combination of in- and out-patient settings where outcomes were not differentiated according to this classification

- primary endpoints were subjective measures (patients' or clinicians') 
- studies where non-e-interventions were mixed with e-interventions and outcomes were not differentiated according to this classification

- studies where medication management outcomes were part of a bundle that included non-medication management outcomes and outcomes were not reported according to this classification

- the intervention was not delivered at point-of-care, in real-time and for an individual patient

- the intervention was only a direct order entry of a medication to be administered by clinic staff, except for immunizations

- simulated interventions

\section{Strategy for identification of eligible studies Electronic searches}

We searched for systematic reviews, randomized controlled trials, non-randomized controlled trials and observational studies that investigated the use of e-applications in medication management in ambulatory care and reported quantifiable outcomes. We performed systematic searches for literature published from 1995 to 2012 in the following databases: Ovid MEDLINE, Ovid EMBASE, Ovid British Nursing Index, ISI Social Science/Science Citation Index, Cochrane Database of Systematic Reviews, Cochrane CENTRAL, Database of Abstracts of Reviews of Effects (DARE), Health Technology Assessment Database (HTA), PubMed and SveMed. The first search was performed in September 2008 and was updated three times. The last search was performed August 8, 2012 (Additional file 1: Table S1).

The search strategy consisted of subject headings and text words covering the concepts of electronic prescriptions and decision support as well as related concepts like medical informatics and electronic patient journal (EPJ) (combined with "prescriptions/medication"). These search terms were combined with terms for ambulatory care/ primary health care or patient safety. We also performed a supplementary broad search in the Cochrane Central EPOC register to retrieve all studies with the subject heading "Information systems" (including subheadings).

\section{Hand-searching}

Hand searches were performed by one investigator (CLC) for relevant studies, i.e. inspection of lists of included studies from relevant systematic reviews (Additional file 2: Table S2) and reference lists from discussion papers and relevant studies.

\section{Study evaluation for inclusion}

Preliminary screening of the identified publications from the first two and fourth systematic searches was carried out independently by pairs of researchers (EJP \& CLC and CLC \& TKD, respectively) who evaluated relevance by reading abstracts and when no abstract was available, based on the title or full text version. One reviewer (CLC) evaluated titles and abstracts found on the third systematic search. We retrieved full-text articles for all studies judged as relevant. Two researchers (CLC \& TKD) independently evaluated studies in their full-text version for inclusion and we discussed and agreed upon inclusion of the studies.

\section{Data extraction and management}

Two authors (CLC \& TKD) extracted estimates and funding data from randomized controlled trials. There was no disagreement between reviewers. One author (CLC) entered these estimates plus the following data into SPSS data bases for all studies: study design; setting; participants; objectives; intervention; comparator; and any relevant observed outcomes. For all studies, we recorded anecdotal reports of unexpected or adverse events that were reported to have or in the investigators' or authors' opinion, could have signified or caused compromises to patient safety. Study quality of the included RCTs was assessed independently, discussed and agreed upon by two investigators (CLC \& TKD).

\section{Quality assessment}

Two reviewers (CLC, TKD) independently assessed, discussed and agreed upon the quality of the RCTs using a supplemented version of the EPOC checklist [39] (Additional file 3: Table S3). We did not assess quality for the other study designs.

\section{Results}

\section{Results of search and selection process}

We obtained full-text articles for 159 publications by screening titles and abstracts of the 3941 unique studies identified by systematic searches, plus another 17 studies identified from hand searching reference lists in relevant studies and systematic reviews, giving a total of 176 potential studies for inclusion. We did not find any systematic reviews that examined adverse events or harms to patients caused by organizational interventions. Onehundred thirty-seven of these studies were excluded (Figure 1). Thirty-six of these excluded studies were RCTs with relevant interventions, participants and settings but either had no outcomes that were directly related to risks to patient safety, did not report any adverse events or did not monitor for them. As well, 3 non-R,CTs and 21 observational studies were excluded for this reason (Figure 1; Additional file 4: Table S4; Additional file 5: Table S5; Additional file 6: Table S6).

We included 39 individual studies, comprising three study design groups: RCTs $(n=18)$; non-R,CTs $(n=5)$; and observational studies $(\mathrm{n}=16)$ (Additional file 7: Table S7; Additional file 8: Table S8; Additional file 9: Table S9). 


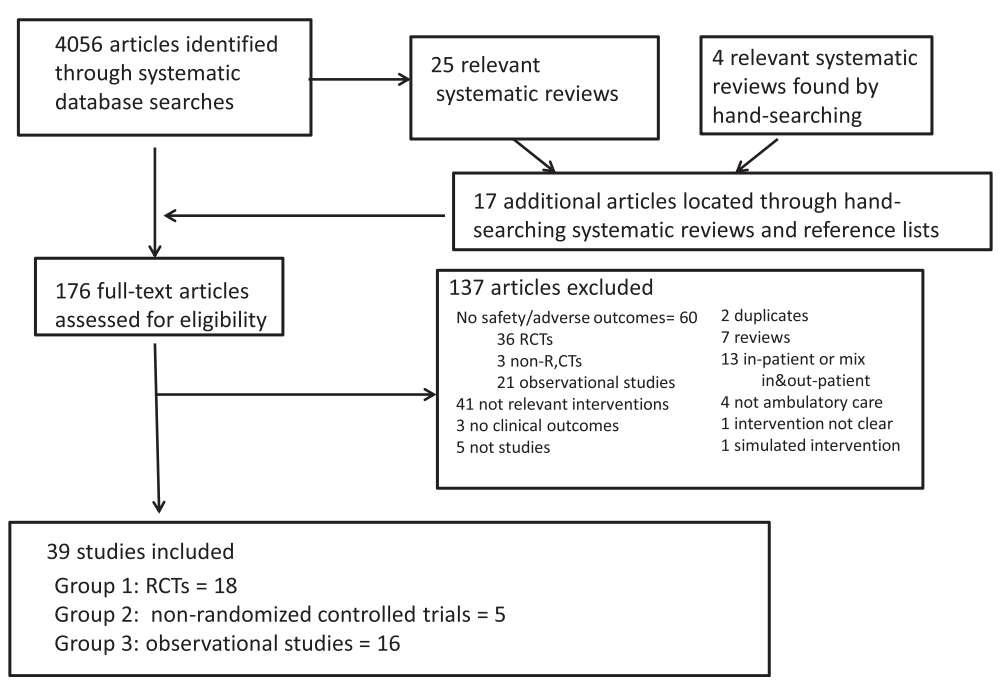

Figure 1 Flow chart of search and selection process.

Randomized controlled trials $(n=18)$

Description of included RCTS

Eighteen randomized controlled trials specified outcomes related to safety, e.g. "unsafe prescribing", "error rate", had adverse events as outcomes, or specified $\grave{a}$ priori that monitoring for adverse events was planned [35,40-56]. Settings for these 18 RCTs were doctors' offices $(n=9$; $50 \%)$, hospital out-patient $(n=6 ; 33 \%)$, both doctors' offices and hospital out-patient clinics $(n=1 ; 6 \%)$, and emergency room $(n=2 ; 11 \%)$ (Additional file 10: Table S10).

E-Rx was investigated in only one RCT, a pragmatic trial [35] along with user-initiated CDSS and an e-application to print paper prescriptions (eGPP). All RCTs investigated CDSS, whereof the CDSS was system-initiated in 16 studies and user-initiated in 2 studies. Uptake of intervention, adherence or non-override of CDSS advice was poor in six of the eight studies that reported this. In all the 10 studies where it was apparent that a EHR was in operation, it was, or appeared to be, in the same digital environment as the CDSS application. In all, eGPP was mentioned to be in use in two RCTs $[35,40]$.

The most frequent drug classes and clinical areas studied were anti-coagulants (5 studies) [42-44,49,56]; other cardiovascular or heart disease management $(n=4)[40,46,48,54]$, and elderly patients $(n=4)$ [45,50-52]. Most of the RCTs were funded by non-industry grants or similar. We found a risk of funding bias in only one study [43]. Quality assessment of included RCTs is provided in Additional file 11: Table S11.

\section{Outcomes for RCTs}

Eleven studies had adverse events or serious negative results as main outcomes $[40,43,44,46-49,51,54-56]$. One of these showed a statistically higher estimated risk of "cardiovascular events" (based on surrogate markers) when
CDSS was compared with a risk chart but no significant differences when the compared was with traditional dosing. However, no actual adverse events were reported, despite explicit monitoring for them [48]. Reduction in risk of injury was statistically significant in [51] and there were statistically significant improvements for heart failure patients' outcomes in [40] and three of seven outcomes for asthma patients [47]. In the remaining studies, there were no significant differences or so low event incidence that calculation of significance was meaningless.

Problematic prescribing or prescriptions (e.g. unsafe/risky prescribing, prescribing errors, unclear prescription) were the outcomes of seven studies [35,41,42,45,50,52,53]. Significantly better results for the intervention group were found in five studies [41,42,45,50,52,53], significantly worse results were found in one study [35] and non-significant differences in the remaining study.

\section{Non-randomized controlled studies $(n=5)$}

Of the five included studies, three investigated CDSS [57-59], one investigated computer-generated paper prescriptions [11], and one investigated e-prescribing [60]. All studies investigated prescribing errors and one included potential adverse drug events as an outcome [11]. No study found any adverse events and other outcomes were either better or unchanged in all studies. One study reported that all errors in the CDSS intervention group were concordant with override of decision support advice [58] (Additional file 12: Table S12).

\section{Observational studies ( $n=16$ )}

Fifteen studies had the following pre-specified outcomes: faulty, risky, unclear prescriptions or prescriptions with errors $(n=11)$ [61-71], unclaimed e-prescriptions $(n=2)$ $[72,73]$, and adverse drug events (ADEs) $(n=3)[62,74,75]$. 
We also included one retrospective series study with main outcome of overriding alerts because the authors reported that the only three ADEs that occurred in the study were consistent with alert non-compliance [76]. In addition, ADEs were anecdotally reported in [63]. Of the four studies that reported before-and-after ADEs, there were fewer ADEs after implementation of computer generated paper prescriptions in one study [74] and better or unchanged incidence after implementation of CDSS in two studies $[62,75]$. Three adverse events were related to interacting drug prescriptions where the prescriber did not comply with CDSS advice [77]. E-prescribing was evaluated in three studies $[61,72,73]$. Only one study [61] showed a result in disfavor of the e-intervention, in that more clarifications were needed by pharmacists for e-prescriptions than for non-e-prescriptions. Two of these studies reported that some patients who did not retrieve their eprescribed drugs at the pharmacy said this was because they had no paper prescription to remind them [72,73]. In one of these [73], 33\% of the unclaimed prescriptions were for "essential drugs. User-interface problems were reported as the cause of prescribing error in two studies. A noncontrolled before-and-after study found errors in CDSS pick-lists and wrong information concerning available formulations and duration of treatment [74]. A retrospective survey reported high rates of discrepancies between freetext and check-off fields on e-prescriptions, of which investigators assessed that $16 \%$ of discrepancies could lead to hospital admission or death [67] (Additional file 13: Table S13).

\section{Discussion}

Randomized and non-randomized controlled trials did not show any adverse patient events. The incidence of adverse events/adverse drug events did not increase postintervention in observational studies. The quality of prescriptions was significantly worse in only one RCT [35] and one pre-post observational study [61]. One non-R,CT reported all prescribing errors were concordant with override of the CDSS advice [58].

From the studies assessed in this review, it appears that observational studies give us most insight into potential causes of adverse events or potential for patient harm. User-interface, faulty programming and erroneous information in the CDSS application were problems that lead to erroneous prescribing [67,74]. Adverse events were found to be concordant with non-adherence to CDSS suggestions [77]. Some patients forgot to pick up e-prescribed drugs for important medications because they had no paper reminder $[72,73]$.

Contrary to the "false expectation" hypothesis, presented in the introduction, that excessive reliance on or confidence in an e-application for medication management would facilitate errors or adverse events, there was low compliance with CDSS advice among the eight RCTs that reported this, consistent with other's findings [76,78] and all adverse events in two studies were concordant with CDSS noncompliance $[58,77]$. This may be due to professionals' skepticism or fear of loss of autonomy, e.g. [79].

\section{Limitations to the review}

As far as we are aware, this is first systematic review to focus on the risks and adverse outcomes of e-interventions for medication management in ambulatory care settings. Its findings, however, are limited, and should be interpreted with caution. We did not find randomized or nonrandomized studies of which the main objective was to evaluate the safety, or, conversely, the risks associated with implementation of e-interventions for medication management in ambulatory care. Only one observational study focused on "unintended consequences" [67]. Although we used an all-inclusive approach, scrutinizing studies of almost any design where an e-intervention was used, only a minority of the individual studies we initially assessed for inclusion were concerned with safety issues at all. Sixtyfive percent of the 99 studies with appropriate interventions, settings and participants that we assessed did not investigate, monitor for or mention anecdotally adverse events or risks to patient safety and therefore were not included in this review. Sixty-six per cent (36) of otherwise eligible RCTs were excluded for this reason, leaving only 18 RCTs for inclusion. Unfortunately, even where adverse events are not the main study outcomes, RCTs are apparently often not powered to reveal seldom or beforehand unknown outcomes or do not have a long-enough or appropriate follow-up. Even non-significant findings of adverse events may indeed have clinical significance, especially if they were made available for meta-analysis [80]. Publication bias $[81,82]$ and funding bias might also contribute to the dearth of published studies investigating or reporting adverse events or patient safety outcomes.

\section{Weaknesses of the review}

It is possible that we did not locate all relevant studies in our searches. Firstly, of studies found in the third systematic search, screening of titles and abstracts, and selection of studies for which to obtain full-text publications was conducted by only one researcher. Secondly, harm or adverse effects are often inadequately reported in the research literature, poorly indexed in the medical databases and might be difficult to identify. Therefore, searching for adverse effects requires highly sensitive search filters with several different subject headings and text words $[25,83]$. It is difficult to create effective adverse effects search filters; therefore better reporting and indexing of adverse effects is required [25]. To overcome this issue, we made a parallel search, not restricted to adverse effects, but for studies performed in ambulatory care settings. However, 
many studies do not have adequate descriptions of the clinical research setting in their abstracts and there is inconsistent use of terminology [84]. There are constantly new studies being published on this topic and it is possible that updates of this review might alter conclusions.

\section{Conclusions}

As so few studies were looking for them, it is not surprising that we found little evidence that might substantiate assertions that implementation of e-applications in medication management in ambulatory settings causes or introduces new untoward risks, adverse events or harms to patients. Until more evidence is sought and presented to disprove the apparently prevailing assumption of the null hypothesis that the e-interventions do not introduce risk, it is premature to conclude that we can fail to reject it.

\section{Implications for practice}

The safety implications of e-medication management in primary care have not been established with results from existing studies found in this systematic review. Regarding, however, the substantial investment necessary to implement e-technologies for medication management and the potential for improving decision making and quality of care, it would be prudent for health care providers to consider attributes of interventions that might have been shown to induce uptake of the intervention or reduce override of CDSS advice (e.g. [85]). For example, there is some evidence that user-initiation of the e-application and forced justification of overrides might facilitate uptake.

Paper reminders for prescription redemption might help patients remember to claim their e-prescribed medications at the pharmacy [72,73]. Faulty programming of CDSS might facilitate patient harm [74] while programming built-in constraints into e-applications might eliminate potentially dangerous rule violations and discrepancies [67].

\section{Implications for research and reporting of research}

Well-designed RCTs are needed to investigate hypothesized untoward and adverse effects of e-interventions for medication management in ambulatory care. It has been suggested that a before and after clustered RCT utilizing an incomplete block design is the optimal approach to evaluate CDSS in primary care [86].

While harm outcomes may be the most sensitive and valid endpoints to evaluate the implementation of systems that effect safety, it is unethical in prospective studies to let the consequences of professional or system errors reach the patient. As well, in the real world, most prescribing errors with potential to cause harm are intercepted before they reach the patient. Surrogate endpoints established as patient safety indicators might be employed. Factors instrumental to observed errors should be determined and alleviated. Valid and reliable methods to assess the potential severity of errors and other surrogate end-points should be developed.

Investigators conducting studies of the effect of organizational interventions should power their studies and length of follow-up to capture rare, unintended and unsuspected events and publish these findings regardless of statistical significance. Even anecdotal reports of observed risks to patient safety and adverse events can inform future study hypotheses and design.

We encourage investigators to improve reporting quality with use of the CONSORT statement, especially the extended version for cluster randomized trials [87]. In reporting studies of e-interventions for medications management, authors should be explicit about which specific applications were studied, their features and implementation strategy, and should consider using standard definitions. As well, clearer descriptions of the study methodology and more consistent use of study design labels would be helpful to perform a more efficient search for observational studies [88].

\section{Additional files}

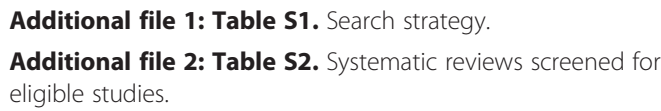

Additional file 3: Table S3. Explanation of quality assessment for included RCTs.

Additional file 4: Table S4. Excluded randomized controlled trials (RCTs) citations.

Additional file 5: Table S5. Excluded non-randomized controlled studies (non-R,CTs) citations.

Additional file 6: Table S6. Excluded observational studies citations. Additional file 7: Table S7. Included randomized controlled trials (RCTs) citations.

Additional file 8: Table S8. Included non-randomized controlled studies citations.

Additional file 9: Table S9. Included observational studies citations. Additional file 10: Table S10. Included randomized controlled studies (RCTs); characteristics and outcomes.

Additional file 11: Table S11. Quality assessment of included RCTs.

Additional file 12: Table S12. Included non-randomized controlled trials (non-R,CTs); characteristics and outcomes.

Additional file 13: Table S13. Included observational studies; characteristics and outcomes.

\section{Competing interests}

The authors declare that they have no financial, professional or personal competing interests in association with the findings of this review. All funding was provided by the Norwegian Knowledge Centre for the Health Services.

\section{Authors' contributions}

CLC takes responsibility for the integrity of the work as a whole, from inception to published review, as the principle researcher, planned and coordinated the review, developed the literature search strategy, selected articles, extracted data, evaluated study quality, wrote the first draft of the paper and revisions; IK developed the systematic search strategy and search algorithm plus revisions, conducted the searches and contributed to writing the first draft; TKD selected studies for inclusion, extracted data and 
evaluated study quality; contributed to revisions of the manuscript; EJP participated in article screening and selection. All authors read and approved the final version of the manuscript.

\section{Acknowledgements}

We would like to thank Louise Forsetlund and Gunn Vist for methodological and practical advice, Louise Forsetlund and Marianne Klemp for their advice in preparing the manuscript and Jan Ødegaard-Jensen for statistical guidance.

Received: 22 March 2013 Accepted: 26 November 2013

Published: 5 December 2013

\section{References}

1. Maryland Health Care Commission: e-Prescribing, An information brief. 2008. [http://mhcc.dhmh.maryland.gov/hit/hie/Documents/sp.mhcc.maryland.gov/ hie/eprescribing/PharmacyBoardReport062408v2.pdf] Accessed 4 Feb 2014.

2. Koppel R, Metlay JP, Cohen A, Abaluck B, Localio AR, Kimmel SE, Strom BL: Role of computerized physician order entry systems in facilitating medication errors. JAMA 2005, 293:1197-1203.

3. Hellström L, Waern K, Montelius E, Astrand B, Rydberg T, Petersson G: Physicians'attitudes towards ePrescribing - evaluation of a Swedish full-scale implementation. BMC Med Inf Decis Mak 2009, 9:37.

4. Health.IT.gov. http://www.cms.gov/Medicare/Quality-Initiatives-PatientAssessment-Instruments/ERxIncentive/index. Accessed 4 Feb 2014.

5. The Norwegian Directorate of Health; 2013. [http://www.helsedirektoratet.no/ it-helse/eresept/Sider/default.aspx] Accessed 2 October 2013.

6. Canadian Medical Association and Canadian Pharmacists Association, e-Prescribing Joint Statement; 2013. http://www.pharmacists.ca/cpha-ca/ assets/File/ePrescribingStatementENG2013.pdf. Accessed 2 October 2013.

7. Agency for Healthcare Research and Quality: Glossary; 2011. http://www psnet.ahrq.gov/glossary.aspx?indexLetter=C. Accessed 24 March 2011.

8. Flottorp S, Oxman AD, Havelsrud K, Treweek S, Herrin J: Cluster randomized controlled trial of tailored interventions to improve the management of urinary tract infections in women and sore throat. BMJ 2002, 325:367.

9. Eccles M, McColl E, Steen N, Rousseau N, Grimshaw J, Parkin D, Purves I: Effect of computerised evidence based guidelines on management of asthma and angina in adults in primary care: cluster randomized controlled trial. BMJ 2002, 325:941.

10. Fretheim A, Oxman AD, Havelsrud K, Treweek S, Kristoffersen DT, Bjorndal A: Rational prescribing in primary care (RaPP): a cluster randomized trial of a tailored intervention. Plos Medicine 2006, 3:0783-0791.

11. Gandhi TK, Weingart SN, Seger AC, Borus J, Burdick E, Poon EG, Leape LL, Bates DW: Outpatient prescribing errors and the impact of computerized prescribing. J Gen Intern Med 2005, 20:837-841.

12. Schiff GD, Rucker TD: Computerized prescribing: building the electronic infrastructure for better medication usage. JAMA 1998, 279:1024-1029.

13. Bates DW, Teich JM, Lee J, Seger D, Kuperman GJ, Ma'Luf N, Boyle D, Leape L: The impact of computerized physician order entry on medication error prevention. J Am Med Inform Assoc 1999, 6:313-321.

14. Kuperman GJ, Gibson RF: Computer physician order entry: benefits, costs, and issues. Ann Intern Med 2003, 139:31-39.

15. Pearson SA, Moxey A, Robertson J, Hains I, Williamson M, Reeve J, Newby D: Do computerised clinical decision support systems for prescribing change practice? A systematic review of the literature (1990-2007) BMC Health Serv Res 2009, 9:154.

16. Kaushal R, Bates DW: Information technology and medication safety: what is the benefit? Qual Saf Health Care 2002, 11:261-265.

17. Grimsmo A: Electronic prescribing- without side-effect? ["Elektronisk resept - uten bivirkninger?"]. Tidsskrift Norsk Lægeforening 2006, 126:1740-1743.

18. Ash JS, Berg M, Coiera E: Some unintended consequences of information technology in health care: the nature of patient care information system-related errors. J Am Med Inform Assoc 2004, 11:104-112.

19. Goldstein MK, Lavori P, Coleman R, Advani A, Hoffman BB: Improving adherence to guidelines for hypertension drug prescribing: cluster-randomized controlled trial of general versus patient-specific recommendations. Am J Manag Care 2005, 11:677-685.

20. Leape LL, Bates DW, Culleb DJ, Cooper J, Demonaco HJ, Galivan T, Hallisay R, Ives J, Laird N, Laffel G, et al: Systems analysis of adverse drug events. JAMA 1995, 274:35-43.
21. Campbell EM, Sittig DF, Ash JS, Guappone KP, Dykstra RH: Types of unintended consequences related to computerized provider order entry. J Am Med Inform Assoc 2006, 13:547-556.

22. Eslami S, Abu-Hanna A, de Keizer NF: Evaluation of outpatient computerized physician medication order entry systems: a systematic review. J Am Med Inform Assoc 2007, 14:400-406.

23. Durieux P, Trinquart L, Colombet I, Nies J, Walton R, Rajeswaran A, Rege Walther M, Harvey E, Burnand B: Computerized advice on drug dosage to improve prescribing practice. Cochrane Database Syst Rev 2008. Issue 3. Art. No.:CD002894 DOI: 10.1002/14651858.CD002894.pub2.

24. Mclntosh HM, Woolacott NF, Bagnall AM: Assessing harmful effects in systematic reviews. BMC Med Res Methodol 2004, 4:19.

25. Golder S, Mcintosh HM, Duffy S, Glanville J: Developing efficient search strategies to identify reports of adverse effects in MEDLINE and EMBASE. Health Info Libr J 2006, 23:3-12.

26. Papanikolaou PN, Christidi GD, loannidis JPA: Comparison of evidence on harms of medical interventions in randomized and nonrandomized studies. CMAJ 2006, 174:635-641

27. Golder S, Loke YK, Bland M: Meta-analyses of adverse effects data derived from randomized controlled trials as compared to observational studies. Methodological overview. PLoS Med 2011, 8:e1001026.

28. Harris AD, McGregor JC, Perencevich EN, Furuno JP, Zhu J, Peterson DE, Finkelstein J: The use and interpretation of quasi-experimental studies in medical informatics. J Am Med Inform Assoc 2006, 13:16-23.

29. Pitrou I, Boutron I, Ahmad N, Ravaud P: Reporting of safety results in published reports of randomized controlled trials. Arch Intern Med 2009, 169:1756-1761.

30. Loke YK, Price D, Herxheimer A: Cochrane Adverse Effects Methods Group.: Systematic reviews of adverse effects: framework for a structured approach. BMC Med Res Methodol 2007, 7:32.

31. Loke YK, Price D, Herxheimer A: Chapter 14: Adverse effects. In Cochrane Handbook for Systematic Reviews of Interventions. Version 5.1.0 [updated March 2011]. Edited by Higgins JPT, Green S. The Cochrane Collaboration; 2011. http://handbook.cochrane.org/chapter_14/14_adverse_effects.htm.

32. Chou R, Aronson N, Atkins D, Ismaila AS, Santaquida P, Smith DH, Wilt TJ, Moher D: AHRQ Series Paper 4: Assessing harms when comparing medical interventions: AHRQ and the Effectiv Health Care Program. J Clin Epidemiol 2010, 63:502-512.

33. Eccles M, Grimshaw M, Campbell M, Ramsay C: Research designs for studies evaluating the effectiveness of change and improvement strategies. Qual Saf Health Care 2003, 12:47-52.

34. Ioannidis JP, Lau J: Evidence on interventions to reduce medical errors: an overview and recommendations for future research. $J$ Gen Intern Med 2001, 16:325-334.

35. Dainty KN, Adhikari NK, Kiss A, Quan S, Zwarenstein M: Electronic prescribing in an ambulatory care setting: a cluster randomized trial. J Eval Clin Pract 2011. [epub ahead of print]. DOl: 10.1111/j.13652753.2011.01657.x.

36. Kaushal R, Kern LM, Barron Y, Quaresimo J, Abramson EL: Electronic prescribing improves medication safety in community-based office practices. J Gen Intern Med 2010, 25:530-536.

37. Bryan C, Boren SA: The use and effectiveness of electronic clinical decision support tools in the ambulatory/primary care setting: a systematic review of the literature. Inform Prim Care 2008, 16:79-91.

38. Health Information Management Society: EHR Electronic Health Record; 2012. http://www.himss.org/asp/topics_ehr.asp Accessed 30August2012.

39. Cochrane Effective Practice and Organisation of Care Group (EPOC): Cochrane Effective Practice and Organisation of Care Review Group Data Collection Checklist. http://epoc.cochrane.org/sites/epoc.cochrane.org/files/ uploads/datacollectionchecklist.pdf.

40. Ansari M, Shlipak MG, Heidenreich PA, Van Ostaeyen D, Pohl EC, Browner WS Massie BM: Improving guideline adherence: a randomized trial evaluating strategies to increase beta-blocker use in heart failure. Circulation 2003, 107:2799-2804.

41. Berner ES, Houston TK, Ray MN, Allison JJ, Heudebert GR, Chatham WW, Kennedy JI Jr, Glandon GL, Norton PA, Crawford MA, et al: Improving ambulatory prescribing safety with a handheld decision support system: a randomized controlled trial. J Am Med Inform Assoc 2006, 13:171-179.

42. Feldstein AC, Smith DH, Perrin N, Yang X, Simon SR, Krall M, Sittig DF, Ditmer D, Platt R, Soumerai SB: Reducing warfarin medication interactions: an interrupted time series evaluation. Arch Intern Med 2006, 166:1009-1015. 
43. Fitzmaurice DA, Hobbs FD, Murray ET, Bradley CP, Holder R: Evaluation of computerized decision support for oral anticoagulation management based in primary care. Br J Gen Pract 1996, 46:533-535.

44. Fitzmaurice DA, Hobbs FDR, Murray ET, Holder RL, Allan TF, Rose PE: Oral anticoagulation management in primary care with the use of computerized decision support and near-patient testing: a randomized, controlled trial. Arch Intern Med 2000, 15:2343-2348.

45. Fortuna RJ, Zhang F, Ross-Degnan D, Campion FX, Finkelstein JA, Kotch JB, Feldstein AC, Smith DH, Simon SR: Reducing the prescribing of heavily marketed medications: a randomized controlled trial. J Gen Intern Med 2009, 24:897-903.

46. Holt TA, Thorogood M, Griffiths F, Munday S, Friede T, Stables D: Automated electronic reminders to facilitate primary cardiovascular disease prevention: randomized controlled trial. $\mathrm{Br} J$ Gen Pract 2010, 60:e137-e143.

47. McCowan C, Neville RG, Ricketts IW, Warner FC, Hoskins G, Thomas GE: Lessons from a randomized controlled trial designed to evaluate computer decision support software to improve the management of asthma. Med Inform Internet Med 2001, 26:191-201.

48. Montgomery AA, Fahey T, Peters TJ, Maclntosh C, Sharp DJ: Evaluation of computer based clinical decision support system and risk chart for management of hypertension in primary care: randomized controlled trial. BMJ 2000, 320:686-690.

49. Poller L, Keown M, Ibrahim S, Lowe G, Moia M, Turpie AG, Roberts C, Van Den Besselaar AMHP, Van Der Meer FJM, Tripodi A, et al: A multicentre randomized assessment of the DAWN AC computer-assisted oral anticoagulant dosage program. Thromb Haemost 2009, 101:487-494.

50. Tamblyn R, Huang A, Perreault R, Jacques A, Roy D, Hanley J, McLeod P, Laprise R: The medical office of the 21 st century (MOXXI): effectiveness of computerized decision-making support in reducing inappropriate prescribing in primary care. CMAJ 2003, 169:549-556.

51. Tamblyn R, Eguale T, Buckeridge DL, Huang A, Hanley J, Reidel K, Shi S, Winslade N: The effectiveness of a new generation of computerized drug alerts in reducing the risk of injury from drug side effects: a cluster randomized trial. J Am Med Inform Assoc 2012, 19:635-643.

52. Terrell KM, Perkins AJ, Dexter PR, Hui SL, Callahan CM, Miller DK: Computerized decision support to reduce potentially inappropriate prescribing to older emergency department patients: a randomized, controlled trial. J Am Geriatr Soc 2009, 57:1388-1394.

53. Terrell KM, Perkins AJ, Hui SL, Callahan CM, Dexter PR, Miller DK: Computerized decision support for medication dosing in renal insufficiency: a randomized, controlled trial. Ann Emerg Med 2010, 56:623-629.

54. Tierney WM, Overhage JM, Murray MD, Harris LE, Zhou XH, Eckert GJ, Smith FE, Nienaber N, McDonald CJ, Wolinsky FD: Effects of computerized guidelines for managing heart disease in primary care. J Gen Intern Med 2003, 18:967-976.

55. Tierney WM, Overhage JM, Murray MD, Harris LE, Zhou XH, Eckert GJ, Smith FE, Nienaber N, McDonald CJ, Wolinsky FD: Can computer-generated evidence-based care suggestions enhance evidence-based management of asthma and chronic obstructive pulmonary disease? A randomized controlled trial. Health Serv Res 2005, 40:477-497.

56. Vadher BD, Patterson DLH, Leaning M: Comparison of oral anticoagulant control by a nurse-practitioner using a computer decision-support system with that by clinicians. Clin Lab Haematol 1997, 3:203-207.

57. Abramson EL, Malhotra S, Fischer K, Edward A, Pfoh ER, Osorio SN, Cheriff A, Kaushal R: Transitioning between electronic health records: effects on ambulatory prescribing safety. J Gen Intern Med 2011, 26:868-874.

58. Kirk RC, Li-Meng GD, Packia J, Min KH, Ong BK: Computer calculated dose in paediatric prescribing. Drug Saf 2005, 28:817-824

59. Malone DC, Saverno KR: Evaluation of a wireless handheld medication management device in the prevention of drug-drug interactions in a medicaid population. J Manage Care Pharm 2012, 18:33-45.

60. Moniz TT, Seger AC, Keohane CA, Seger DL, Bates DW, Rothschild JM: Addition of electronic prescription transmission to computerized prescriber order entry: effect on dispensing errors in community pharmacies. Am J Health-Syst Pharm 2011, 68:158-163.

61. Åstrand B, Montelius E, Petersson G, Ekedahl A: Assessment of ePrescription quality: an observational study at three mail-order pharmacies. BMC Med Inf Decis Mak 2009, 9:8.

62. Cafolla A, Melizzi R, Baldacci E, Pignoloni P, Dragoni F, Campanelli M, Caraccini R, Foa R: "Zeus" a new oral anticoagulant therapy dosing algorithm: a cohort study. Thrombos Res 2011, 128:325-330.
63. Devine EB, Hansen RN, Wilson-Norton JL, Lawless NM, Fisk AW, Blough DK, Martin DP, Sullivan SD: The impact of computerized provider order entry on medication errors in a multispecialty group practice. J Am Med Inform Assoc 2010, 17:78-84.

64. Ginzburg R, Barr WB, Harris M, Munshi S: Effect of a weight-based prescribing method within an electronic health record on prescribing errors. Am J Health-Syst Pharm 2009, 66:2037-2041.

65. Humphries TL, Carroll N, Chester EA, Magid D, Rocho B: Evaluation of an electronic critical drug interaction program coupled with active pharmacist intervention. Ann Pharmacother 2007, 41:1979-1985.

66. Nanji KC, Rothschild JM, Salzberg C, Keohane CA, Zigmont K, Devita J, Gandhi TK, Dalal AK, Bates DW, Poon EG: Errors associated with outpatient computerized prescribing systems. J Am Med Inform Assoc 2011, 18:767-773.

67. Palchuk MB, Fang EA, Cygielnik JM, Labreche M, Shubina M, Ramelson HZ, Hamann C, Broverman C, Einbinder JS, Turchin A: An unintended consequence of electronic prescriptions: prevalence and impact of internal discrepancies. J Am Med Inform Assoc 2010, 17:472-476.

68. Schwarz EB, Parisi SM, Handler SM, Koren G, Cohen ED, Shevchik GJ, Fischer GS: Clinical decision support to promote safe prescribing to women of reproductive age: a cluster-randomized trial. J Gen Intern Med 2012, 27:831-838.

69. Varkey P, Aponte P, Swanton C, Fischer D, Johnson SF, Brennan MD: The effect of computerized physician-order entry on outpatient prescription errors. Manag Care Interface 2007, 20:53-57.

70. Volmer D: Use of a generic protocol in documentation of prescription errors in Estonia, Norway and Sweden. Pharmacy Practice 2012, 10(2):72-77.

71. Zillich AJ, Shay K, Hyduke B, Emmendorfer TR, Mellow AM, Counsell SR, Supiano MA, Woodbridge P, Reeves P: Quality improvement toward decreasing high-risk medications for older veteran outpatients. J Am Geriatr Soc 2008, 56:1299-1305.

72. Ekedahl A, Mansson N: Unclaimed prescriptions after automated prescription transmittals to pharmacies. Pharm World Sci 2004, 26:26-31.

73. Kinnaird D, Cox T, Wilson JP: Unclaimed prescriptions in a clinic with computerized prescriber order entry. Am J Health-Syst Pharm 2003, 60:1468-1470.

74. Bizovi KE, Beckley BE, McDade MC, Adams AL, Lowe RA, Zechnich AD, Hedges JR: The effect of computer-assisted prescription writing on emergency department prescription errors. Acad Emerg Med 2002, 9:1168-1175.

75. Steele AW, Eisert S, Witter J, Lyons P, Jones MHA, Gabow P, Ortiz E: The effect of automated alerts on provider ordering behavior in an outpatient setting. Plos Medicine 2005, 2:864-870.

76. Hetlevik I, Holmen J, Kruger O, Kristensen P, Iversen H, Furuseth K: Implementing clinical guidelines in the treatment of diabetes mellitus in general practice - Evaluation of effort, process, and patient outcome related to implementation of a computer-based decision support system. Int J Technol Assess Health Care 2000, 16:210-227.

77. Weingart SN, Toth M, Sands DZ, Aronson MD, Davis RB, Phillips RS: Physicians'decisions to override computerized drug alerts in primary care. Arch Intern Med 2003, 163:2625-2631.

78. van der Sijs H, Aarts J, Vulto A, Berg M: Overriding of drug safety alerts in computerized physician order entry. J Am Med Inform Assoc 2006, 13:138-147.

79. Murray MD, Harris LE, Overhage JM, Zhou XH, Eckert GJ, Smith FE, Buchanan NN, Wolinsky FD, McDonald CJ, Tierney WM: Failure of computerized treatment suggestions to improve health outcomes of outpatients with uncomplicated hypertension: results of a randomized controlled trial. Pharmacotherapy 2004, 24:324-337.

80. loannidis JPA: Adverse events in randomized trials neglected, restricted, distorted, and silenced. Arch Intern Med 2009, 169:1737-1739.

81. Hopewell S, Loudon K, Clarke MJ, Oxman AD, Dickersin K: Publication bias in clinical trials due to statistical significance or direction of trial results. Cochrane Database Syst Rev 2009, 1:MR000006.

82. Montori VM, Smieja M, Guyatt GH: Publication bias: a brief review for clinicians. Mayo Clin Proc 2000, 75:1284-1288.

83. Golder $S$, Loke Y: Search strategies to identify information on adverse effects: a systematic review. J Med Libr Assoc 2009, 97:84-92.

84. Roberts NW, Gill PJ, Wang KY, Heneghan C: Developing a Search Filter for Identifying Primary Care Studies in General Medical Journals. P1A32. Spain: Abstracts of the 2011 Cochrane Colloquium Madrid; 2011:53-54. 
85. Mollon B, Chong J, Holbrook AM, Sung M, Thabane L, Foster G:

Features predicting the success of computerized decision support for prescribing: a systematic review of randomized controlled trials. BMC Med Inf Decis Mak 2009, 9:11.

86. Eccles M, Grimshaw J, Steen N, Parkin D, Purves I, McColl E, Rousseau N: The design and analysis of a randomized controlled trial to evaluate computerized decision support in primary care: the COGENT study. Fam Pract 2000, 17:180-186.

87. Campbell MK, Elbourne DR, Altman DG: CONSORT statement: extension to cluster randomized trials. Br Med J 2004, 328:702-708.

88. Vandenbroucke JP, von Elm E, Altman DG, Gøtzsche PC, Mulrow CD, Pocock SJ, Poole C, Schlesselman JJ, Egger M: Strengthening the Reporting of Observational Studies in Epidemiology (STROBE): explanation and elaboration. PLoS Med 2007, 4:e297.

doi:10.1186/1472-6947-13-133

Cite this article as: Carling et al:: Risks to patient safety associated with implementation of electronic applications for medication management in ambulatory care - a systematic review. BMC Medical Informatics and Decision Making 2013 13:133.

\section{Submit your next manuscript to BioMed Central and take full advantage of:}

- Convenient online submission

- Thorough peer review

- No space constraints or color figure charges

- Immediate publication on acceptance

- Inclusion in PubMed, CAS, Scopus and Google Scholar

- Research which is freely available for redistribution 